\title{
CATECHOL AMINE EXCRETION BY DUODENAL ULCER PATIENTS *
}

\author{
By WILLIAM R. WADDELL, GEORGE D. ZUIDEMA AND GENE M. SMITH
}

\author{
(From the Departments of Surgery and Anesthesia, Harvard Medical School, the Surgical \\ and Anesthesia Services, Massachusetts General Hospital, and the Department \\ of Nutrition, Harvard School of Public Health, Boston, Mass.)
}

(Submitted for publication October 21, 1959; accepted February 12, 1960)

Despite recognition of the importance of central nervous system function in the control of gastric secretory and motor processes and the general acceptance of the concept that duodenal ulcer is associated with abnormal nervous influence upon the stomach, there is little objective evidence concerning the exact mechanisms involved. The main hindrance to collecting data for examining the relationships between nervous and gastric functions in patients has been the lack of techniques for measuring the functional status of the autonomic nervous system. The present report concerns the results of a comparative evaluation of autonomic function in ulcer patients and in normal subjects by determination of urinary excretion of free epinephrine and norepinephrine. The results of two separate experiments are reported.

\section{METHODS}

First experiment. Urine and gastric juice collections were made before and after administration of peptone broth, histamine, and insulin to 10 male ulcer patients and 10 nonulcer male control subjects (1). None of the control subjects gave a past history of gastrointestinal symptoms suggestive of peptic ulcer. Seven of the control subjects were normal, healthy individuals; they came to the hospital immediately prior to the testing, having carried out their normal activities on the preceding day. These 7 control subjects were paid volunteers selected so that each could be matched with one of the ulcer patients on the basis of age and general level of activity. The remaining 3 control subjects were hospitalized for illnesses other than duodenal ulcer. One had carcinoma of the rectum, one chronic cholecystitis, and one had mild cholangitis secondary to a partial stricture of the bile ducts. All of the ulcer patients had active ulcers at the time the tests were carried out. Five were ambulatory and came to the hospital for these

\footnotetext{
* This investigation was supported in part by a grant from the United States Public Health Service [A-1836 (R1) ], by a contract between the Massachusetts General Hospital and the United States Air Force [49(638)98], and The Fund for Research and Teaching, Department of Nutrition, Harvard School of Public Health.
}

tests, as did the 7 healthy volunteer control subjects. Of the remaining 5 ulcer patients, 2 were on the surgical wards with the immediate prospect of operation and the other 3 were on the medical wards. None of the hospitalized patients (either control or ulcer) was confined to bed. Sedatives and anticholingeric medications were omitted for at least 12 hours before the tests.

Each subject was tested on 2 separate days. The tests began each day at 7:30 a.m. after an overnight fast. On the first day the subject voided and then lay quietly in bed with his head end inclined to a $45^{\circ}$ angle. Most of this first hour was occupied with psychological testing. After 1 hour the subject stood beside the bed to void the first urine sample. Immediately after this a Levin tube was passed into the stomach and adjusted to aspirate freely. ${ }^{1}$ Twenty minutes later the collection of gastric juice was begun. Six 10-minute "basal" samples of gastric juice were collected, and at the end of this period the patient again stood to void a second sample of urine. Both urine collections are referred to as "basal" samples. After the second voiding, $80 \mathrm{ml}$ of peptone broth was introduced into the stomach via the tube, which was then clamped for 20 minutes. Following this the stomach was emptied and 6 additional 10-minute samples of gastric juice were obtained. At the end of this period the bladder was again emptied. Histamine diphosphate, $0.5 \mathrm{mg}$, was then administered subcutaneously and 6 more 10-minute samples of gastric juice were collected. At the end of the hour a final collection of urine was made.

On the second day of testing a similar routine was followed. After the first 2 hours (during which 2 "basal" urine samples and 1 "basal" gastric collection were obtained) 12 units of regular insulin was injected intravenously. Thereafter, six 30 -minute samples of gastric juice were collected and the patient voided 1.5 and 3 hours after insulin administration. Blood sugar concentration was measured before the insulin was given and at 30 and 60 minutes thereafter. Blood sugar concentration was reduced to below $50 \mathrm{mg}$ per $100 \mathrm{ml}$ in all ulcer patients and in all but one control subject.

The volume of each sample of gastric juice was measured, the $\mathrm{pH}$ determined on a Beckman calomel-glass electrode $\mathrm{pH}$ meter, the acidity titrated to $\mathrm{pH} 3.5$ with $0.1 \mathrm{~N} \mathrm{NaOH}$ by an electrometric method, and the

\footnotetext{
1 As nearly as can be determined from the hospital records, only one of the ulcer patients and one control subject had had a Levin tube passed before this experiment.
} 
TABLE I

Experiment 1: Gastric secretion of ten ulcer patients and ten control subjects under basal conditions and after stimulation with peptone broth, histamine, or insulin (means and standard errors)

\begin{tabular}{|c|c|c|c|c|c|c|}
\hline Control subjects & Volume & $\mathrm{pH}$ & Free acid & Free acid & Chloride & Chloride \\
\hline $\begin{array}{l}\text { Basal (1st day) } \\
\text { Basal (2nd day) } \\
\text { Peptone } \\
\text { Histamine } \\
\text { Insulin }\end{array}$ & $\begin{array}{c}m l / h r \\
55 \pm 9.9 \\
52 \pm 12.2 \\
79 \pm 14.4 \\
104 \pm 17.0 \\
79 \pm 13.5\end{array}$ & $\begin{array}{l}3.25 \pm 0.79 \\
3.73 \pm 0.82 \\
2.71 \pm 0.71 \\
2.16 \pm 0.63 \\
2.74 \pm 0.74\end{array}$ & $\begin{array}{c}m E q / L \\
23 \pm 6.9 \\
15 \pm 4.4^{*} \\
40 \pm 10.9 \\
59 \pm 12.2 \\
44 \pm 10.7\end{array}$ & $\begin{array}{l}m E q / h r \\
1.0 \pm 0.3 \\
1.1 \pm 0.5 \\
3.9 \pm 1.3 \\
7.4 \pm 1.7 \\
5.5 \pm 1.6\end{array}$ & $\begin{array}{c}m E q / L \\
110 \pm 8.2 \\
104 \pm 6.9 \\
119 \pm 7.9 \\
124 \pm 9.0 \\
126 \pm 7.2\end{array}$ & $\begin{array}{l}m E q / h r \\
6.2 \pm 1.3 \\
5.5 \pm 1.2 \\
9.0 \pm 1.9 \\
14.0 \pm 2.4 \\
11.0 \pm 2.0\end{array}$ \\
\hline Ulcer patients & & & & & & \\
\hline $\begin{array}{l}\text { Basal (1st day) } \\
\text { Basal (2nd day) } \\
\text { Peptone } \\
\text { Histamine } \\
\text { Insulin }\end{array}$ & $\begin{array}{c}52 \pm 6.5 \\
68 \pm 14.9 \\
97 \pm 17.0 \\
134 \pm 18.5 \\
114 \pm 17.2\end{array}$ & $\begin{array}{l}3.02 \pm 0.53 \\
2.21 \pm 0.43 \\
1.65 \pm 0.21 \\
1.23 \pm 0.06 \\
1.68 \pm 0.24\end{array}$ & $\begin{array}{l}15 \pm 5.0 \\
30 \pm 6.3^{*} \\
50 \pm 7.5 \\
77+7.0 \\
60 \pm 6.9\end{array}$ & $\begin{array}{r}1.0 \pm 0.4 \\
2.7 \pm 0.9 \\
5.5 \pm 1.4 \\
11.1 \pm 2.0 \\
7.9 \pm 1.8\end{array}$ & $\begin{array}{r}99 \pm 8.7 \\
115 \pm 3.5 \\
120 \pm 5.4 \\
134 \pm 4.0 \\
134 \pm 3.5\end{array}$ & $\begin{array}{r}5.3 \pm 1.0 \\
7.9 \pm 1.7 \\
11.9 \pm 2.1 \\
18.3 \pm 2.7 \\
15.6 \pm 2.5\end{array}$ \\
\hline
\end{tabular}

* The difference between the two groups with respect to free acid output during the "basal" period of the second day was the only difference in Table I which reached the 0.10 level of significance using a two-tailed $t$ test.

chloride concentration measured by the method of Wilson and Ball (2).

Immediately after collection, the volume of each urine sample was measured and the entire specimen acidified to $\mathrm{pH} 2$ to 3 with $6 \mathrm{~N}$ hydrochloric acid. These samples were then frozen and stored for later analysis. The determination of epinephrine and norepinephrine in these urine samples was made by DuToit's modification of the fluorometric method of von Euler and Floding, ion exchange resin for purification being utilized (3). The sensitivity, reproducibility and other factors pertaining to the use of this method are discussed at length in DuToit's report (3). Most of the measurements reported below were made in his laboratory.

Second experiment. Ten male control subjects, without history of duodenal ulcer, were matched with 11 male ulcer patients with respect to age and general level of physical activity. None of these ulcer or control subjects had been used in the first experiment. All but one of the ulcer patients had active ulcers at the time of testing. Four of the control subjects and 7 of the ulcer subjects were hospitalized; all 4 of the former and 3 of the latter were tested the day following their admission to the hospital.

Each subject collected a 12-hour urine sample from 7 a.m. to 7 p.m. while carrying out his regular day's work or other activities. The hospitalized subjects were up and about the ward for the entire 12-hour period. Among the nonhospitalized control subjects were 3 plumbers, 1 electrician, 1 animal farm worker and 1 hospital administrator. The nonhospitalized ulcer patients included 1 auto mechanic, 2 salesmen and 1 electrician. Between 7 p.m. and 7 a.m. of the same day, each subject remained flat in bed except to stand while voiding. The urine collected during this second period is referred to as the night sample; that collected during the preceding 12 hours is called the day sample.

\section{RESULTS}

First experiment. Although the mean volume and titratable acidity of gastric juice were higher,

TABLE II

Experiment 1: Epinephrine and norepinephrine excretion in urine by ten ulcer patients and ten control subjects (micrograms per hour)

\begin{tabular}{|c|c|c|c|c|c|c|c|c|c|c|}
\hline & & & \multicolumn{8}{|c|}{ After stimulation } \\
\hline & \multicolumn{2}{|c|}{ "Basal" } & \multicolumn{2}{|c|}{ Peptone } & \multicolumn{2}{|c|}{ Histamine } & \multicolumn{2}{|c|}{ Insulin $(0-90 \mathrm{~min})$} & \multicolumn{2}{|c|}{ Insulin $(90-180 \mathrm{~min})$} \\
\hline & $\mathrm{E}$ & $\mathrm{N}$ & $\mathrm{E}$ & $\mathrm{N}$ & $\mathrm{E}$ & $\mathrm{N}$ & $\mathrm{E}$ & $\mathrm{N}$ & $\mathrm{E}$ & $\mathbf{N}$ \\
\hline $\begin{array}{l}\text { Control subjects } \\
\text { Mean } \\
\text { SE }\end{array}$ & $\begin{array}{l}0.50 \\
0.09\end{array}$ & $\begin{array}{l}2.38 \\
0.36\end{array}$ & $\begin{array}{l}0.63 \\
0.26\end{array}$ & $\begin{array}{l}2.39 \\
0.40\end{array}$ & $\begin{array}{l}0.37 \\
0.10\end{array}$ & $\begin{array}{l}2.45 \\
0.51\end{array}$ & $\begin{array}{l}3.18 \\
1.00\end{array}$ & $\begin{array}{l}3.12 \\
0.60\end{array}$ & $\begin{array}{l}2.49 \\
0.64\end{array}$ & $\begin{array}{l}2.53 \\
0.53\end{array}$ \\
\hline $\begin{array}{l}\text { Ulcer patients } \\
\text { Mean } \\
\text { SE }\end{array}$ & $\begin{array}{l}0.32 \\
0.06\end{array}$ & $\begin{array}{l}1.31 \\
0.20\end{array}$ & $\begin{array}{l}0.33 \\
0.08\end{array}$ & $\begin{array}{l}0.85 \\
0.31\end{array}$ & $\begin{array}{l}0.68 \\
0.41\end{array}$ & $\begin{array}{l}2.40 \\
0.83\end{array}$ & $\begin{array}{l}2.36 \\
0.30\end{array}$ & $\begin{array}{l}1.48 \\
0.23\end{array}$ & $\begin{array}{l}0.88 \\
0.24\end{array}$ & $\begin{array}{l}1.22 \\
0.28\end{array}$ \\
\hline$t$ Value & 1.65 & 2.60 & 1.09 & 3.05 & 0.73 & 0.05 & 0.78 & 2.55 & 2.34 & 2.18 \\
\hline Probability & NS* & 0.02 & NS & 0.01 & NS & NS & NS & 0.05 & 0.05 & 0.05 \\
\hline
\end{tabular}

* Not significant. 


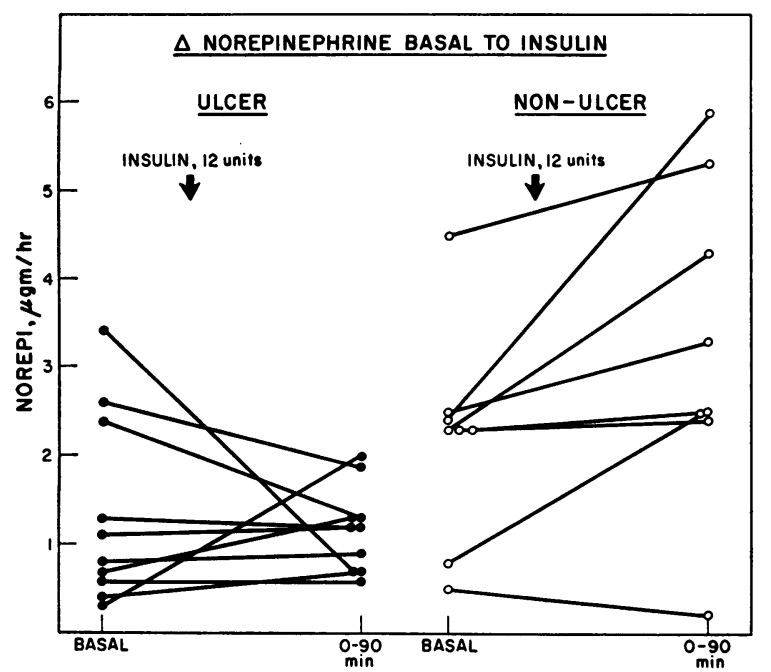

Fig. 1. Urinary NOREPINEPhrine excretion by ten DUODENAL ULCER PATIENTS AND EIGHT CONTROL SUBJECTS DURING BASAL PERIODS AND SUBSEQUENT STIMULATION BY INSULIN HYPOGLYCEMIA. Two control subjects were unable to void 90 minutes after injection of insulin.

and the $\mathrm{pH}$ lower, for the ulcer patients than for the control subjects, the variation was great and only one (basal free acid) of the differences between the two groups reached the 0.10 level of significance with a two-tailed $t$ test (Table I).

Urinary excretion of free catechol amines was lower in ulcer patients than in control subjects. The difference between the two groups with respect to excretory rate of norepinephrine during the basal periods reached the 0.02 level of significance; that for epinephrine was not significant at the 0.10 level. During subsequent periods of stimulation of gastric secretion with peptone broth or insulin, the mean norepinephrine output of the ulcer patients was significantly lower than that of the control subjects. During the second 90-minute period after stimulation with insulin, the ulcer subjects had significantly lower mean epinephrine excretions than did the control subjects. The mean figures and results of the statistical evaluations are given in Table II.

A point which should be stressed is that the comparisons between basal catechol amine output of ulcer and control subjects (reported in Table II) are not based on single samples; they are based on four separate samples combined. This multiple sampling technique was used to minimize the influence of chance factors, associ- ated with changes in the test environment, which might influence the catechol output. In addition to the comparisons based on the four basal samples combined, comparisons between ulcer and control subjects were made for each of the four samples (Day 1-Hour 1, Day 1-Hour 2, Day 2-Hour 1, and Day 2-Hour 2) considered separately. In all four comparisons the norepinephrine output of the ulcer subjects was found to be significantly lower than that of the control subjects; three of the comparisons were significant at the 0.05 level and one at the 0.10 level using a two-tailed test. Three of the four comparisons based on the basal epinephrine data indicated lower epinephrine output in ulcer than in control subjects, but only one of those comparisons was significant at the 0.10 level.

The ulcer patients and control subjects were found to differ in response to stimulation by hypoglycemia during the first 90 minutes. As is seen in Figure 1, the ulcer patients, considered as a group, had lower norepinephrine excretory rates before injection of insulin than did the control subjects. During the first 90 minutes after injection the difference between the two groups was even more pronounced. The difference in mean response of the two groups was significant at the 0.10 level.

The gastric secretory data were examined in relation to the catechol data to determine whether the two were correlated. In general, they were found not to be significantly correlated. For example, the change in gastric output due to histamine stimulation was not correlated with the change in norepinephrine output due to histamine.

TABLE III

Experiment 2: Epinephrine and norepinephrine excretion in urine by eleven ulcer patients and ten control subjects (micrograms per hour)

\begin{tabular}{lccccc}
\hline & \multicolumn{2}{c}{ Day sample } & & \multicolumn{2}{c}{ Night sample } \\
\cline { 2 - 3 } \cline { 5 - 6 } & $\mathrm{E}$ & $\mathrm{N}$ & & $\mathrm{E}$ & $\mathrm{N}$ \\
\hline Control subjects & & & & & \\
$\quad$ Mean & 0.39 & 1.82 & & 0.17 & 1.10 \\
$\quad$ SE & 0.10 & 0.15 & & 0.05 & 0.10 \\
Ulcer patients & & & & & \\
$\quad$ Mean & 0.23 & 1.87 & & 0.11 & 0.66 \\
$\quad$ SE & 0.06 & 0.22 & & 0.03 & 0.09 \\
$t$ Value & 1.31 & 0.20 & & 1.02 & 3.36 \\
Probability & $\mathrm{NS}$ & $\mathrm{NS}$ & & $\mathrm{NS}$ & 0.01 \\
& & & & & \\
\hline
\end{tabular}


Second experiment. During the night the 11 ulcer patients had lower catechol output than did the 10 control subjects. As is seen in Table III the difference between the two groups, with respect to norepinephrine output, reached the 0.01 level of significance with a two-tailed $t$ test; the difference with respect to epinephrine was not significant at the 0.10 level. During the day the ulcer patients, considered as a group, were not significantly different from the control subjects with regard to either norepinephrine or epinephrine excretion.

\section{DISCUSSION}

Catechol excretion and urine volume. The findings of major concern in this report are that ulcer subjects had lower mean norepinephrine output than did control subjects under basal conditions, after stimulation with peptone or insulin (Experiment 1) and at night (Experiment 2). The possibility was considered that these findings might have been influenced by a correlation between output of norepinephrine and urine or by a lower urine volume in ulcer than in control subjects. Analyses using the Spearman rank correlation statistic (4) revealed low positive correlations between output of norepinephrine and urine in Experiment 1 under basal conditions $(\rho=+0.25)$, after stimulation with peptone $(\rho=+0.32)$ and after stimulation with insulin $(\rho=+0.18)$; in Experiment 2 the correlations were low and negative at night $(\rho=-0.09)$ and during the day $(\rho=-0.25)$. None of these correlations reached the 0.10 level of significance using a two-tailed test and all were too small to be considered consequential.

The mean urine volume of ulcer subjects was found to be lower than that of control subjects in Experiment 1 under basal conditions and after stimulation both with peptone and insulin; however, the only difference which reached the 0.10 level of significance occurred after stimulation with peptone broth. In Experiment 2 the mean urine volume of ulcer subjects was higher than that of the control subjects both at night and during the day. The difference in the case of the day samples was significant at the 0.05 level; that for the night samples was not significant at the 0.10 level. Because the ulcer subjects in Experi- ment 1 were found to have lower volumes of urine output than did the control subjects, additional analyses were carried out based on an index of catechol output divided by urine volume. These analyses indicated that the ulcer subjects tended to excrete less norepinephrine per unit of urine than did control subjects under all conditions in both experiments; the differences were statistically significant, however, only after stimulation with insulin in Experiment 1 and during accumulation of night samples in Experiment 2.

Environmental factors. In the first experiment the catechol collections were made under a variety of conditions which might have influenced catechol output. For example, the subjects were given psychological tests during accumulation of the first hour basal samples and were intubated during accumulation of the second hour basal samples. Analyses failed to reveal any significant differences between Hour 1 and Hour 2 catechol output either on Day 1 or Day 2 for either ulcer or control subjects.

The possibility of a "novelty" or "first-time" effect in Experiment 1 was examined in two ways. First, the catechol output of the first experimental day was compared with that of the second. These analyses revealed no difference between Day 1 and Day 2 with respect to norepinephrine excretion but indicated a significantly greater mean epinephrine output on the first than on the second day, both for the ulcer and control groups. Secondly, the catechol output of the first hour of the first experimental day was compared with the mean of the other three basal samples. Both ulcer and control subjects showed no significant difference with respect to rate of norepinephrine output but had significantly higher epinephrine rates during the first than during the subsequent three basal periods; in addition both groups showed lower urine volumes during the first basal period than during the subsequent basal periods. The question to be considered is whether these indications of a "first-time" effect militate against the conclusion that ulcer subjects have lower norepinephrine excretory rates than do control subjects. Two facts suggest that the answer is negative. In the first experiment the norepineprhine output of ulcer subjects was found to be significantly lower than that of control subjects during the last three basal periods as well 
as during the first; in the second experiment it was the second 12-hour sample (night) rather than the first (day sample) which showed a significant difference between norepinephrine output of ulcer and of control subjects.

Reproducibility of catechol data in Experiment 1. Spearman correlation coefficients (4) were computed to assess the similarity of the Hour 1 and Hour 2 catechol data. The results indicated good reproducibility in the case of norepinephrine $(\rho$ values were $+0.70,+0.58,+0.69$ and +0.84$)$ but poor reproducibility in the case of epinephrine ( $\rho$ values were $-0.02,+0.52,-0.21$ and $-0.01)$. To determine the reproducibility of the catechol data on two different days, the Hour 1 and Hour 2 data of Day 1 were summed and correlated with the summed data of Day 2. It was found that the control subjects had good reproducibility both with respect to epinephrine ( $\rho=$ $+0.67)$ and norepinephrine $(\rho=+0.60)$ but that the ulcer subjects had poor reproducibility both with respect to epinephrine $(\rho=+0.08)$ and norepinephrine $(\rho=+0.13)$.

General comments. The most important conclusion arising from the investigations presented above is that ulcer patients have lower norepinephrine excretion than do individuals without ulcers; significant differences were found under "basal" conditions during the day, at rest during the night, and after stimulation with peptone broth or insulin. There were suggestions that the ulcer subjects might also be lower than control subjects with respect to epinephrine output but most of the comparisons were not statistically significant. Whether this nonsignificance was due to the generally low reliability (reproducibility) of the epinephrine data or due to a genuine absence of difference between ulcer and control subjects with respect to epinephrine output, cannot be determined on the basis of the present data.

Although there is substantial evidence of a close correlation between urinary excretion of catechol amine and sympathetic activity (5), it does not seem justifiable to assume that the low norepinephrine output of the ulcer patients is an indisputable indication of low sympathetic activity. Some metabolic difference, such as activity of deaminating enzyme systems or other hormone effects, could conceivably result in lower free catechol amine excretion in the urine of ulcer patients.
However, pending some definite evidence of such mechanisms, the assumption that low catechol amine output in urine of ulcer patients is indicative of low sympathetic activity seems warranted and perhaps helpful in expanding our approach to the problems of control of gastric secretion and duodenal ulceration. It is not proposed that low sympathetic activity is the only disturbance of autonomic function underlying the ulcer diathesis but rather than this is one aspect of a complex central nervous system dysfunction, probably involving the hypothalamus and associated reflex centers.

\section{SUMMARY}

Two experiments were conducted comparing urinary free catechol amine excretion of male ulcer patients and normal control subjects. In the first experiment urine and gastric secretory collections were made before and after administration of peptone broth, histamine, and insulin. Urinary excretion of epinephrine and norepinephrine was lower in ulcer patients than in control subjects under "basal" conditions and after stimulation with peptone broth and insulin; all differences with respect to norepinephrine output were significant at the 0.05 level or better. The ulcer patients had higher volume, higher titratable acidity of gastric juice and lower $\mathrm{pH}$ than did the control subjects, but most comparisons were not significant at the 0.10 level. The increased output of norepinperhine due to insulin hypoglycemia was greater $(p=0.10$ level $)$ in the control subjects than in those with ulcers. In general, changes in gastric secretion were not found to be correlated with changes in catechol output.

In the second experiment a different group of ulcer patients and normal controls collected day and night urine samples. The epinephrine and norepinephrine output of ulcer patients and control subjects did not differ significantly during the day. The night urine samples of ulcer patients contained significantly less norepinephrine $(p=0.01)$ than those of the control subjects.

Analyses based on an index of catechol output divided by urine volume indicated that the ulcer subjects tended to excrete less norepinephrine per unit of urine than did control subjects under all conditions in both experiments; the differences were statistically significant, however, only after 
stimulation with insulin in Experiment 1 and during accumulation of night samples in Experiment 2 .

\section{ACKNOWLEDGMENT}

The technical assistance of the Misses Nancy Hurley, Katherine Monahan, Ester Trulli, Luba Geller and Ann Lecomte is gratefully acknowledged. We are also indebted to the late Dr. C. H. DuToit for assistance with the analytical procedures.

\section{REFERENCES}

1. Smithwick, R. H., and Kneisel, J. J. Effect of resection of sympathetic and parasympathetic in- nervation of stomach upon gastric acidity. Rev. Gastroent. 1950, 17, 439.

2. Wilson, D. W., and Ball, S. G. Study of estimation of chloride in blood and serum. J. biol. Chem. 1928, 79, 221.

3. DuToit, C. H. A study of chemical methods for quantitative measurements of catechol amines. Wright Air Development Center Technical Report 59-175, Wright-Patterson Air Force Base, Ohio. April, 1959.

4. Siegel, S. Nonparametric Statistics for the Behavioral Sciences. New York, McGraw-Hill Book Company, 1956, p. 202.

5. von Euler, U. S. Noradrenaline. Springfield, Ill., Charles C Thomas, 1956, ch. X, XI, XII. 